\title{
Incidence, presentation, diagnosis, and management of malfunctioning implantable cardioverter-defibrillator rate-sensing leads
}

\begin{abstract}
Recognition of tachyarrhythmia by an implantable cardioverter-defibrillator (ICD) requires an intact rate-sensing lead. We retrospectively examined 266 consecutive patients requiring an ICD to characterize the incidence, clinical presentation, diagnosis, and management of a defective rate-sensing lead. To identify clinical parameters that may contribute to lead complications, we also assessed the effects of age, gender, type of rate-sensing lead, manufacturer of the lead, and surgeon. Over a follow-up period of $30 \pm 22$ months (mean \pm standard deviation), a defective lead was found in $9(3.4 \%)$ patients, in $9(1.7 \%)$ of 514 leads over a period of 2 to 39 (mean $17 \pm 15$ ) months after implantation. Except for 1 patient, in whom a lead fracture was incidently found during ICD generator replacement, these patients had multiple inappropriate shocks of recent onset. Clinical parameters were not helpful in identifying patients at risk for lead complication. An abnormal beeping signal obtained while the patients performed various maneuvers was helpful in confirming a defect. All of the defective leads were epicardial. These cases were managed by placement of a transvenous endocardial lead. (AM HEART J 1994;128:892-5.)
\end{abstract}

Emile G. Daoud, MD, ${ }^{a}$ Marvin M. Kirsh, MD, ${ }^{b}$ Steven F. Bolling, MD, ${ }^{b}$ S. Adam Strickberger, $\mathrm{MD},{ }^{a}$ Fred Morady, $\mathrm{MD}^{\mathrm{a}}$ and William $\mathrm{H}$. Kou, $\mathrm{MD}^{\mathrm{a}}$

Ann Arbor, Mich.

Recognition of ventricular tachyarrhythmias by an implantable cardioverter-defibrillator (ICD) depends primarily on sensing the rate of the arrhythmia. Therefore accurate rate-counting is fundamental to proper function of the ICD system. Ratecounting is achieved by the rate-sensing circuit of the device, which uses either a transvenous coaxial lead within the right ventricle or a pair of unipolar screw-in leads placed on the epicardium. Although previous studies have reported defective rate-sensing leads, ${ }^{1-4}$ the clinical profile of patients in whom lead complications occur has not been investigated. The purpose of this study was to describe the incidence, clinical presentation, diagnosis, and management of ICD malfunction attributable to a defective ratesensing lead.

\footnotetext{
From the aSection of Cardiology, Department of Internal Medicine and the bepartment of Thoracic Surgery, Veterans Affairs Medical Center and the University of Michigan Hospital.

Received for publication Dec. 17, 1993; accepted Feb. 1, 1994.

Reprint requests: William H. Kou, MD, Section of Cardiology (111A), Vet erans Affairs Medical Center, 2215 Fuller Road, Ann Arbor, MI 48105.

Copyright (C) 1994 by Mosby-Year Book, Inc.

$0002-8703 / 94 / \$ 3.00+0 \quad \mathbf{4} / \mathbf{1} / \mathbf{5 8 1 3 2}$
}

\section{METHODS}

Study population. The study population consisted of 266 consecutive patients who underwent implantation of an ICD at the University of Michigan Hospital or the Ann Arbor Veterans Affairs Medical Center between March 1987 and July 1992 . There were 218 men and 48 women. Their mean age was $60 \pm 22$ years (mean $\pm \mathrm{SD}$ ). The underlying heart disease consisted of coronary artery disease in $202(76 \%)$, idiopathic cardiomyopathy in $41(15 \%)$, valvular heart disease in $11(4 \%)$, other heart disease in 4 $(2 \%)$, and no identifiable heart disease in $8(3 \%)$. Aborted sudden cardiac death with documented ventricular fibrillation (VF) had occurred in 186 patients, and recurrent syncope or presyncope caused by ventricular tachycardia (VT) had occurred in 80 patients.

Implantation of rate-sensing lead. All of the ICD pulse generators, defibrillation patch electrodes, and transvenous rate-sensing leads were manufactured by Cardiac Pacemakers, Inc. (St. Paul, Minn.). The myocardial screw-in rate-sensing leads were manufactured by Cardiac Pacemakers, Inc. and Daig, Inc. (Minnetonka, Minn.). In 248 patients, a pair of myocardial screw-in leads was used for rate sensing. These leads and a pair of defibrillation patch electrodes were placed on the epicardium through a median sternotomy. The myocardial leads were placed on the surface of the right ventricular anterior wall in 242 patients and on the left ventricular lateral wall in 6 patients who al- 
ready had a cardiac pacemaker lead within the right ventricle. A transvenous endocardial rate-sensing lead was inserted in 18 patients in whom an epicardial defibrillation patch electrode was placed through a left thoracotomy. The transvenous rate-sensing lead and spring coil lead were inserted into a subclavian vein and positioned in the right ventricular apex and at the right atrial-superior vena caval junction.

Placement of implantable cardioverter defibrillator generator. After an acceptable VF defibrillation threshold had been confirmed, the proximal portions of the leads were pulled through a subcutaneous tunnel to the ICD pocket in the left subcostal area. ICDs capable only of delivering shocks were used in 261 patients; ICDs also capable of antitachycardia pacing were used in 5 patients. Before discharge from the hospital, the ICD was tested to confirm reliable sensing and conversion of VT and VF.

Patient follow-up. After discharge, the patients were seen in an outpatient clinic every 2 or 3 months during the first year after implantation and every 1 to 3 months thereafter. For each ICD shock, the presence or absence of syncope or other symptoms was recorded. The shocks were confirmed by the programmer during each visit. In patients in whom frequent ICD discharges occurred, outpatient or in-hospital electrocardiographic monitoring was performed to determine whether arrhythmias were triggering the discharges. These patients also were asked to bend and twist at the waist, reach up with their arms, cough, and perform Valsalva's maneuver after a magnet had been positioned over the pulse generator to detect abnormal beeping signals. Audible tones not corresponding to a QRS complex on a simultaneous electrocardiogram indicated a malfunctioning of the ICD sensing system. This finding prompted exploration of the ICD pocket to evaluate directly the rate-sensing leads. The evaluation consisted of careful visual examination of the lead and measurement of the pacing threshold and lead impedance. If either or both of these measurements were abnormal, the lead was considered defective and a new lead implanted.

Statistical analysis. Continuous variables are expressed as the mean $\pm \mathrm{SD}$. Differences between continuous variables were tested by Student's $t$ test, and differences between categorical variables were tested by chi square analysis. A $p$ value $<0.05$ was considered significant.

\section{RESULTS}

Incidence of defective leads. Of 496 epicardial and 18 endocardial rate-sensing leads, a defect was found in $9(1.7 \%)$ epicardial leads in $9(3.4 \%)$ patients over a period of $30 \pm 22$ months of follow-up. The duration from implantation to presentation of the defective lead was $17 \pm 15$ (range 2 to 39 ) months. Lead malfunction occurred in 5 patients within the first year, in one patient in the second year, in one patient in the third year, and in two patients in the fourth year after implantation. Analysis of selected clinical parameters including gender, age, type of lead (transvenous endocardial vs screw-in epicardial), manufac-
Table I. Comparison of clinical profile of patients with and without a defective rate-sensing lead

\begin{tabular}{lcc}
\hline & $\begin{array}{c}\text { Patients without } \\
\text { defective leads } \\
(n=257)\end{array}$ & $\begin{array}{c}\text { Patients with } \\
\text { defective leads } \\
(n=9)\end{array}$ \\
\hline Age (yr, mean \pm SD) & $60 \pm 11$ & $60 \pm 10$ \\
Male & $209\left(81^{\prime}\right.$ & $9\left(100^{\circ}\right)$ \\
Type of lead & & \\
Endocardial & 239 & 0 \\
Epicardial & 18 & 9 \\
Manufacturer & 205 & 9 \\
Daig, Inc. & 52 & 0 \\
Cardiac Pacemakers, Inc. & & 6 \\
Surgeon & 144 & 1 \\
A & 87 & 0 \\
B & 10 & 0 \\
C & 8 & 2 \\
D & 8 & \\
Other & & \\
\hline
\end{tabular}

$p>0.05$ for all comparisons.

turer, and surgeon indicated that there were no significant differences between the patients with and those without a defective lead (Table I).

Clinical manifestations and diagnosis of lead malfunction. Eight patients initially had frequent ICD discharges of recent onset (shocks in seven patients and shocks and antitachycardia pacing in one) that were not preceded by any symptoms and that occurred during minimal body movement (Table II). Holter or in-hospital telemetric electrocardiographic monitoring documented that ICD shocks were delivered during sinus rhythm in five patients. Inappropriate rate-sensing was confirmed by abnormal beeping signals in these eight patients. Chest and abdominal radiographs were obtained in seven patients, and in none was a fracture line in a lead seen. With direct evaluation of the leads in five patients, a high impedance $(>1000 \Omega)$ and a pacing threshold of $>10 \mathrm{~V}$ were found in four patients, and a fracture line was visually noted at the neck of the lead near the ICD connector in the fifth patient. In the ninth patient, a fracture line was seen incidentally at the neck of the lead near the ICD connector during pulse generator replacement. Multiple ICD shocks had never occurred in this patient before the replacement. In none of these patients was there a loose screw cap or a loose connection in the header slots.

Management and follow-up. In all patients, the lead defect was managed by implanting a transvenous endocardial rate-sensing lead in the right ventricular apex via the left subclavian vein. The lead was then tunneled subcutaneously to the ICD pulse generator. Normal sensing was later confirmed by the absence 
Table II. Clinical profile of patients in whom rate-sensing lead was defective

\begin{tabular}{|c|c|c|c|c|c|c|c|}
\hline Patient & Sex & $\begin{array}{l}\text { Age } \\
(y r)\end{array}$ & $\begin{array}{c}\text { Time since } \\
\text { implantation } \\
\text { (mo) }\end{array}$ & Clinical presentation & $\begin{array}{c}\text { Beeping } \\
\text { signal }\end{array}$ & $\begin{array}{l}\text { Finding on } \\
\text { lead }\end{array}$ & Follow-up \\
\hline 1 & $\mathbf{M}$ & 49 & 13 & $\begin{array}{l}15 \text { Shocks in } 9 \text { days; } \\
\text { Holter monitor } \\
\text { documentation of } \\
\text { shocks during sinus } \\
\text { rhythm }\end{array}$ & Abnormal & & No shock in $13 \mathrm{mo}$ \\
\hline 2 & $\mathbf{M}$ & 55 & 36 & 8 Shocks in $2 \mathrm{mo}$ & Abnormal & $\begin{array}{l}\text { High pacing } \\
\text { threshold }(>10 \mathrm{~V}) \\
\text { and impedance } \\
(>1000 \Omega)\end{array}$ & No shock in 3 mo \\
\hline 3 & M & 70 & 9 & $\begin{array}{l}7 \text { Shocks and } 7 \\
\text { antitachycardia } \\
\text { pacing in } 2 \text { days }\end{array}$ & Abnormal & Fracture line at neck & 1 Shock in $8 \mathrm{mo}$ \\
\hline 4 & M & 72 & 11 & $\begin{array}{l}6 \text { Shocks in } 10 \text { days; } \\
\text { Holter monitor } \\
\text { documention of } \\
\text { shocks during sinus } \\
\text { rhythm }\end{array}$ & Abnormal & $\begin{array}{l}\text { High pacing } \\
\text { threshold }(>10 \mathrm{~V}) \\
\text { and inpedance } \\
(>1000 \Omega)\end{array}$ & No shock in 4 mo \\
\hline 5 & $\mathbf{M}$ & 44 & 2 & 4 Shocks in 4 days & Abnormal & $\begin{array}{l}\text { High pacing } \\
\text { threshold }(>10 \mathrm{~V}) \\
\text { and impedance } \\
(>1000 \Omega)\end{array}$ & No shock in 6 mo \\
\hline 6 & $\mathbf{M}$ & 66 & 10 & $\begin{array}{l}10 \text { Shocks in } 36 \text { hours; } \\
\text { telemetric monitor } \\
\text { documentation of } \\
\text { shocks during sinus } \\
\text { rhythm }\end{array}$ & Abnormal & & 4 Shocks in $28 \mathrm{mo}$ \\
\hline 7 & $\mathbf{M}$ & 57 & 7 & $\begin{array}{l}4 \text { Shocks in } 1 \text { wk; } \\
\text { Holter monitor } \\
\text { documentation of } \\
\text { shocks during sinus } \\
\text { rhythm }\end{array}$ & Abnormal & $\begin{array}{l}\text { High pacing } \\
\text { threshold }(>10 \mathrm{~V}) \\
\text { and impedance } \\
(>1000 \Omega)\end{array}$ & No shock in $3 \mathrm{mo}$ \\
\hline 8 & M & 60 & 37 & $\begin{array}{l}7 \text { Shocks in } 3 \text { mo; } \\
\text { Holter monitor } \\
\text { documentation of } \\
\text { shocks during sinus } \\
\text { rhythm }\end{array}$ & Abnormal & & No shock in 12 mo \\
\hline 9 & $\mathbf{M}$ & 66 & 39 & None & Not done & Fracture line at neck & No shock in $23 \mathrm{mo}$ \\
\hline
\end{tabular}

of an abnormal beeping signal during various body movements. The defective leads were capped and left in place. During a mean follow-up of $11 \pm 9$ months after implantation of the new rate-sensing lead, seven patients had no recurrence of ICD discharges. One patient had one shock in 8 months, and another patient had four shocks in 28 months. These events were sporadic and usually preceded by symptoms consistent with VT or VF.

\section{DISCUSSION}

During a mean postimplantation interval of 30 months, in $3.4 \%$ of patients with an ICD, or $9(1.7 \%)$ of 512 leads, the rate-sensing lead malfunctioned. The most common clinical manifestation of lead malfunction was the occurrence of multiple inappro- priate ICD discharges. The interval from implantation to detection of lead malfunction was 2 to 39 months.

Previous reports. A malfunctioning rate-sensing lead causing inappropriate ICD discharges is a wellrecognized complication of ICD therapy. The incidence has been reported to be $0.7 \%$ to $3.8 \% .^{1-4}$ The $1.7 \%$ incidence of lead malfunction in the present study is consistent with those results.

Diagnosis. Except for the incidental discovery of a fractured lead during ICD pulse generator replacement in one patient, all patients had recent multiple ICD discharges that were not preceded by symptoms and that occurred during activities such as walking, sitting up, and arm-stretching. Because most currently available ICD devices do not have electrogram 
storage capability and because appropriate shocks are not necessarily preceded by symptoms, ${ }^{5}$ the diagnosis of a defective rate-sensing lead depends primarily on close, continuous observation. A sudden increase in the frequency of ICD discharges in a patient with a stable clinical course may indicate lead malfunction and should prompt an evaluation of the integrity of the rate-sensing lead. It is also important to check the functional specifications of the leads at the time of pulse generator replacement. Without that check, the diagnosis of a lead fracture in one patient in this series may have been delayed.

Other investigators ${ }^{6,7}$ have evaluated the usefulness of the "heep-o-gram" to detect malfunctioning of the ICD-sensing system. Ballas et al. ${ }^{7}$ concluded that it is a reliable and sensitive means of detecting sensing abnormalities, as was the case in the present study. It is important to ask the patient to perform simple exercises (e.g., sitting up or bending and stretching at the waist) during the evaluation because beep monitoring performed only at rest may not detect a defective lead.

Cause of lead malfunction. Fracture was the cause of lead malfunction in five patients-one confirmed by direct visualization of a fracture line, three by the presence of a high lead impedance, and one by direct visualization of a fracture line and high lead impedance. In the remaining three patients, the cause was unknown. The ICD sensing circuit was not the source of excessive sensing in these three patients: the same pulse generator was used after placement of a new lead, and inappropriate shocks did not recur. The two leads that had a visible fracture line had fractured at the same site, the neck of the lead. It is possible that this location is vulnerable to damage caused by the traction used to pull the lead subcutaneously to the generator during implantation. Therefore it may be important to avoid applying excessive traction when tunneling the leads to the generator pocket.

Potential proarrhythmic complications. Although no proarrhythmic complication of the inappropriate shocks was observed in this study, several reports have documented the induction of malignant ventricular tachyarrhythmias by an R-wave-synchronized ICD shock delivered during sinus tachycardia or supraventricular tachyarrhythmias. ${ }^{8-10}$ In these case reports, the ICD was able to detect the induced ventricular tachyarrhythmia and to deliver rescue shocks. However, Cohen et al. ${ }^{\bar{\gamma}}$ reported a case in which subsequent shocks failed to restore sinus rhythm. Because a defective rate-sensing lead often causes the ICD pulse generator to discharge during sinus rhythm, patients are exposed to an unnecessary additional risk of malignant ventricular tachyarrhythmias and of syncope or even death. Therefore, physicians should consider a rate-sensing lead complication in patients who have frequent ICD discharges.

We thank Penny Weaver for excellent secretarial assistance in the preparation of the manuscript.

\section{REFERENCES}

1. Echt DS, Armstrong K, Schmidt P, Oyer PE, Stinson EB, Winkle RA. Clinical experience, complications and survival in 70 patients with the automatic implantable cardioverter/defibrillator. Circulation 1985;71: 289-96.

2. Kelly PA, Cannom DS, Garan H, Mirabal GS, Harthorne JW, Hurvitz RJ, Vlahakes GJ, Jacobs ML, Ilvento JP, Buckley MJ, Ruskin JN. The automatic implantable cardioverter-defibrillator: efficacy, complications and survival in patients with malignant ventricular arrhythmias. J Am Coll Cardiol 1988;11:1278-86.

3. Winkle RA, Mead RH, Ruder MA, Gaudiani VA, Smith NA, Buch WS, Schmidt P, Shipman T. Long-term outcome with the automatic implantable cardioverter-defibrillator. J Am Coll Cardiol 1989;6:1353. 61.

4. Marchlinski FE, Flores BT, Buxton AE, Hargrove WC, Addonizio VP, Stephenson LW, Harken AH, Doherty JU, Grogan EW, Josephson ME. The automatic implantable cardioverter-defibrillator: efficacy, complications, and device failures. Ann Intern Med 1986;104:481-8.

5. Tchou PJ, Kadri N, Anderson J, Caceres JA, Jazayeri M, Akhtar M. Automatic implantable cardioverter defibrillator survival of patients with left ventricular dysfunction and malignant ventricular arrhythmias. Ann Intern Med 1988;109:529-34.

6. Chapman PD, Troup P. The automatic implantable cardioverter defibrillator: evaluating suspected inappropriate shocks. I Am Coll Cardiol 1986;7:1075-8.

7. Ballas SJ, Rashidi R, McAlister H, Corbelli R, McCowan R, Wilkoff BL, Castle LW, Morant VA, Simmons TW, Maloney JD. The use of beepo-grams in the assessment of automatic implantable cardioverter defibrillator sensing function. PACE 1989;12:1737-45.

8. Cohen TJ, Chien WW, Lurie KG, Lee MA, Lesh MD, Scheinman MM Griffin JC. Implantable cardioverter defibrillator pro-arrhythmia: case report and review of the literature. PACE 1991:14:1326-9.

9. Kou WH, Kirsh MM, Stirling MC, Kadish AH, Orringer CE, Morady F. Provocation of ventricular tachycardia by an automatic implantable cardioverter defibrillator. AM HEART J 1990;120:208-11.

10. Manz M, Gerckens U, Luderitz B. Erroneous discharge from an implanted automatic defibrillator during supraventricular tachyarrhythmia induced ventricular fibrillation. Am * Cardiol 1986;57:343-4. 